\title{
Electronics reliability assessment of future power fusion machines: neutron interaction analysis in bulk silicon
}

\author{
J.L. Autran*, D. Munteanu \\ Aix-Marseille University \& CNRS, IM2NP (UMR 7334), Faculté des Sciences - Service 142, \\ Avenue Escadrille Normandie Niémen, F-13397 Marseille Cedex 20, France
}

\begin{abstract}
The interactions of high energy neutrons produced in D-D and D-T nuclear fusion reactions with natural silicon have been investigated through direct calculation using nuclear cross section libraries, MCNP6 and Geant4 numerical simulations. From the systematic simulation and particle tracking of $5 \times 10^{8}$ neutrons incident on a $1 \mathrm{~cm}^{2} \times 20 \mu \mathrm{m}$ bulk target, we provide a detailed analysis of all interactions (elastic, inelastic, nonelastic) per type of reacting silicon isotope and an exhaustive classification of all neutron-induced secondary products as a function of their type, energy, linear energy transfer and range in silicon. Implications for reliability of the electronics in future power fusion machines are discussed based on these first evaluations.
\end{abstract}

\section{Keywords}

D-D neutron, D-T neutron, neutron interactions, natural silicon, silicon isotopes, Geant4, MCNP6, SRIM, ENDF/B-VII.1, soft-error rate, single event upset. 


\section{Highlights}

- Interactions between natural silicon, $2.45 \mathrm{MeV}$ and $14 \mathrm{MeV}$ neutrons are studied

- At $14 \mathrm{MeV}, 40 \%$ of elastic, $30 \%$ of inelastic and $30 \%$ of nonelastic events are produced

- At $2.45 \mathrm{MeV}, 75 \%$ of elastic and $25 \%$ of inelastic events are produced

- Implications for reliability assessment of the electronics in future power fusion machines are discussed.

\section{* Corresponding author:}

Prof. Jean-Luc Autran, IM2NP - UMR CNRS 7334, Faculté des Sciences - Service 142, Avenue Escadrille Normandie - F-13397 Marseille Cedex 20 France - Phone: + 33 (0)413 594627 - Email: jean-luc.autran@univ$\underline{\text { amu.fr }}$ 


\section{Introduction}

Deuterium-tritium (D-T) and deuterium-deuterium (D-D) nuclear fusion reactions are the most interesting and important reactions for magnetic and inertial confinement approaches envisaged to develop future carbon-free source of energy based on the same principle that powers the stars [1]. In both cases, an extremely high level of energetic neutrons will be produced during power fusion operation, creating a residual neutron irradiation field outside the reaction chamber. Of course, the radiation conditions will be very different for D-D and D-T plasma operations, the latter being the most challenging for electronics, with the production of primary $14.1 \mathrm{MeV}$ neutrons against 2.45 MeV neutrons in the D-D plasma operation. Because all future fusion reactors will contain a large amount of electronics part for command and diagnostic operations of such complex large systems, many of these parts will be exposed to nuclear radiation and negatively affected by this environment condition. Nuclear radiation can damage or destroy electronic devices or sensors, corrupt signals in analogue or digital circuits, corrupt data in memories, etc. In fusion machines, these effects can appear progressively, due to accumulated ionization or accumulated atomic displacements, or instantaneously, due to single neutron interactions inducing the so-called Single Event Effects (SEE) [2].

In this work, such neutrons interactions at the origin of SEEs in fusion experiments have been explored. In a first approach, monoenergetic D-D (2.45 MeV) and D-T (14.1 MeV) neutrons reactions with silicon material have been investigated through direct calculation using nuclear cross section libraries and performing numerical simulations with two different radiation transport codes, MCNP6 [3-4] and Geant4 [5-6]. Details about these different approaches are given in section 2. From these systematic simulations of a large amount of neutrons incident on a natural silicon bulk target, we provide in section 3 a detailed analysis of all interactions per type of reacting silicon isotope and an exhaustive classification of all neutron-induced secondary products as a function of their type, energy, linear energy transfer and range in silicon. Finally, implications for reliability electronics in future power fusion installations are discussed in section 4 on the basis of these first evaluations.

\section{Direct calculation and numerical simulation details}

In the following, we consider a thin silicon layer with an area of $\mathrm{S}=1 \mathrm{~cm}^{2}$ and a thickness of $\mathrm{e}=20 \mu \mathrm{m}$ corresponding to the order of magnitude of the volume of a typical microelectronics integrated circuit in bulk architecture in which neutron-silicon interactions that occur may deposit energies in the sensitive parts of the circuit. The composition of this target corresponds to natural silicon: it contains $92.20 \%$ of isotope ${ }^{28} \mathrm{Si}$, $4.70 \%$ of 
${ }^{29} \mathrm{Si}$ and $3.10 \%$ of ${ }^{30} \mathrm{Si}$ with a total atomic density equal to $\mathrm{N}=5 \times 10^{22}$ at. $/ \mathrm{cm}^{3}$, which corresponds to a material density of $2.32 \mathrm{~g} / \mathrm{cm}^{3}$.

The susceptibility of this layer to neutron irradiation in the fusion machine context, as discussed below in section 4 , can be roughly evaluated via the calculation of the number of neutron-silicon interactions when it is subjected to 2.45 or $14.1 \mathrm{MeV}$ monoenergetic neutrons. Such a calculation can be performed following two approaches: i) a direct analytical calculation using neutron cross section library data or ii) a numerical estimation using a Monte Carlo radiation transport code. In this latter case, in addition to the amount of interactions, a simulation run can provide more detailed information when the code is able to track secondary particles, as it is possible to do with Geant4 for example.

In this work, the ENDF/B-VII.1 evaluated neutron library [7] has been considered for a direct calculation of neutron interactions in the defined target. From these data (extracted from [8]), the number of interactions in the target at a given neutron energy $\mathrm{E}$ is simply given by:

$$
R(E)=\sum_{i} f_{i} \sigma_{i}(E) \times 10^{-24} \times N e \times M
$$

where $\sigma_{i}$ is the value at energy $E$ of the cross section for isotope $i$ (in barn), $f_{i}$ is the fraction of isotope $i$ in the target isotopic composition, e is the target thickness, $\mathrm{N}$ is the number of atoms per unit volume and $\mathrm{M}$ is the number of incident monoenergetic neutrons, in this work fixed to the arbitrary value $M=5 \times 10^{8}$ for standardization purpose (fixed in other studies [9-11], M corresponds to the number of high energy atmospheric neutrons - above $1 \mathrm{MeV}$ - impacting a surface of $1 \mathrm{~cm}^{2}$ at sea level exposed to natural radiation during $25 \times 10^{6} \mathrm{~h}$ ).

As mentioned above, an alternative to the direct calculation is numerical simulation using a Monte Carlo radiation transport code. In the present work, both MCNP6 and Geant4 were used. Geant4 version 4.9.4 patch 01 was used for these simulations following a methodology used in previous works [9-11]. In particular, the list of physical processes employed was based on the standard package of physics lists QGSP_BIC_HP [12]. Other simulation details can be found in Ref. [10].

Outputs of Geant4 simulation consist in a series of files containing all the information related to the neutron interaction events in the silicon target material. For each event, this information includes the nature and the coordinates of the vertex of the interaction, the energy of the incident neutron, the exhaustive list of secondary particles produced during the interaction, the energy and the emission direction vector for each of these emitted particles. All these records have been post-treated and formatted into final interaction databases (text files) following two compilation rules: i) we eliminated in the output file (raw data) all secondaries below $1 \mathrm{keV}$ of energy; ii) we also eliminated all $\gamma$ photons, $\pi^{0}, \mathrm{e}^{+}, \mathrm{e}^{-}$and $\eta$ particles, these particles being not able to deposit 1 
$\mathrm{keV}$ of energy in the targets, which is a necessary condition to observe single event effects in electronics. We completed information related to secondary particles by computing the linear energy transfer (LET) and the range of each secondary product using the SRIM code (Stopping and Range of Ions in Matter [13-14]), following an automatized procedure described in Ref. [10].

Finally, Monte Carlo N-Particle (MCNP) version 6.2 was used in this work to allow a quantitative comparison with respect to Geant 4 results, mainly because this code is very popular and considered as a simulation standard for nuclear applications and in neutronics. PTRAC card options were activated to obtain, for each event, the nature and the coordinates of the vertex of the interaction and the final energy of the neutron after the interaction. Such information allowed us to classify and to count interactions as a function of the target atom $\left({ }^{28} \mathrm{Si}\right.$, ${ }^{29} \mathrm{Si}$ or ${ }^{30} \mathrm{Si}$ ) and as a function of the nature (elastic, inelastic, nonelastic) of the interaction.

\section{Simulation results}

\section{A. Estimations of the numbers of interaction events}

Tables I and II report the number of elastic, inelastic and nonelastic events produced in the $1 \mathrm{~cm}^{2} \times 20 \mu \mathrm{m}$ natural silicon target subjected to $5 \times 10^{8}$ monoenergetic neutrons of $2.45 \mathrm{MeV}$ and $14.1 \mathrm{MeV}$ and evaluated using direct calculation and numerical simulation. We recall, at this level, that the interactions of neutrons with atomic nuclei can occur via two main mechanisms [15]: scattering (which can be subdivided in elastic and inelastic processes) and capture (also called non-elastic). When a neutron is involved in an elastic scattering, the nature of the interacting particles is not modified; in particular the recoil nucleus is then the same as the target nuclei, here silicon. There is no threshold energy for this kind of interaction. Similarly, during an inelastic scattering, the impacted target nucleus undergoes an internal rearrangement into an excited state from which eventually releases radiation. The energy threshold for neutrons is around $1.8 \mathrm{MeV}$ in the case of silicon nuclei. Instead of being scattered, an incident neutron may be absorbed or captured by a target silicon nucleus. Many reactions are possible, and a large variety of particles can be emitted. This type of interaction is also called nonelastic interaction. Threshold energy depends on the reaction scheme, as indicated in Table II. 
Table I. Elastic and inelastic reactions in a natural silicon target $\left(1 \mathrm{~cm}^{2} \times 20 \mu \mathrm{m}, 5 \times 10^{8} \mathrm{n}\right)$ with $2.45 \mathrm{MeV}$ and 14 MeV neutrons estimated from ENDFB-VII.1 direct calculations, Geant4 and MCNP6 numerical simulations.

\begin{tabular}{|c|c|c|c|c|c|c|c|c|}
\hline \multirow{3}{*}{$\begin{array}{c}\text { Isotope of } \\
\text { natural } \\
\text { silicon }\end{array}$} & \multirow{3}{*}{ Reaction } & \multirow{3}{*}{$\begin{array}{c}\text { Threshold } \\
\text { (MeV) }\end{array}$} & \multicolumn{6}{|c|}{ Number of reactions $\left(1 \mathrm{~cm}^{2} \times 20 \mu \mathrm{m}, 5 \times 10^{8} \mathrm{n}\right)$} \\
\hline & & & \multicolumn{2}{|c|}{ ENDFB-VII.1 } & \multicolumn{2}{|c|}{ Geant4 } & \multicolumn{2}{|c|}{ MCNP6 } \\
\hline & & & $2.45 \mathrm{MeV}$ & $14 \mathrm{MeV}$ & $2.45 \mathrm{MeV}$ & $14 \mathrm{MeV}$ & $2.45 \mathrm{MeV}$ & $14 \mathrm{MeV}$ \\
\hline \multirow{2}{*}{$\begin{array}{c}{ }^{28} \mathrm{Si} \\
(92.22 \%)\end{array}$} & $\begin{array}{l}{ }^{28} \mathrm{Si}(\mathrm{n}, \mathrm{n})^{28} \mathrm{Si} \\
\quad(\text { Elastic) }\end{array}$ & $\sim 0$ & 86,207 & 33,653 & 85,710 & 32,812 & 86,100 & 30,798 \\
\hline & $\begin{array}{l}{ }^{28} \mathrm{Si}(\mathrm{n}, \mathrm{n}){ }^{28} \mathrm{Si}^{*} \\
\text { (Inelastic) }\end{array}$ & 1.78 & 29,042 & 23,972 & 28,754 & 24,042 & 28,677 & 24,161 \\
\hline \multirow{2}{*}{$\begin{array}{c}{ }^{29} \mathrm{Si} \\
(4.68 \%)\end{array}$} & $\begin{array}{l}{ }^{29} \mathrm{Si}(\mathrm{n}, \mathrm{n})^{29} \mathrm{Si} \\
\quad(\text { Elastic) }\end{array}$ & $\sim 0$ & 4,513 & 1,880 & 4,335 & 1,705 & 4,467 & 1,648 \\
\hline & $\begin{array}{l}{ }^{29} \mathrm{Si}(\mathrm{n}, \mathrm{n})^{29} \mathrm{Si}^{*} \\
\text { (Inelastic) }\end{array}$ & 1.8 & 1,433 & 1,504 & 1,397 & 1,910 & 1,441 & 1,823 \\
\hline \multirow{2}{*}{$\begin{array}{c}{ }^{30} \mathrm{Si} \\
(3.09 \%)\end{array}$} & $\begin{array}{l}{ }^{30} \mathrm{Si}(\mathrm{n}, \mathrm{n})^{30} \mathrm{Si} \\
\quad(\text { Elastic) }\end{array}$ &,$\sim 0$ & 3,565 & 1,132 & 3,475 & 1,113 & 3,531 & 1,043 \\
\hline & $\begin{array}{l}{ }^{30} \mathrm{Si}(\mathrm{n}, \mathrm{n}){ }^{30} \mathrm{Si}^{*} \\
\text { (Inelastic) }\end{array}$ & 1.8 & 1,131 & 961 & 294 & 893 & 312 & 1,598 \\
\hline \multicolumn{3}{|c|}{ TOTAL } & 125,891 & 62,783 & 123,965 & 62,475 & 124,528 & 61,071 \\
\hline
\end{tabular}

Table II. Nonelastic reactions in a natural silicon target $\left(1 \mathrm{~cm}^{2} \times 20 \mu \mathrm{m}, 5 \times 10^{8} \mathrm{n}\right)$ with $14 \mathrm{MeV}$ neutrons estimated from ENDFB-VII.1 direct calculation, Geant4 and MCNP6 numerical simulations.

\begin{tabular}{|c|c|c|c|c|c|c|}
\hline \multirow{2}{*}{$\begin{array}{l}\text { Isotope of } \\
\text { natural } \\
\text { silicon }\end{array}$} & \multirow{2}{*}{$\begin{array}{l}\text { Nonelastic } \\
\text { reaction }\end{array}$} & \multirow{2}{*}{$\begin{array}{c}\text { Threshold } \\
\text { (MeV) }\end{array}$} & \multicolumn{4}{|c|}{ Number of reactions $-14 \mathrm{MeV}\left(1 \mathrm{~cm}^{2} \times 20 \mu \mathrm{m}, 5 \times 10^{8} \mathrm{n}\right)$} \\
\hline & & & \multicolumn{2}{|c|}{ Geant4 } & MCNP6 & ENDFB-VII.1 \\
\hline \multirow{5}{*}{$\begin{array}{c}{ }^{28} \mathrm{Si} \\
(92.2 \%)\end{array}$} & ${ }^{28} \mathrm{Si}(\mathrm{n}, \mathrm{p})^{28} \mathrm{Al}$ & 4.00 & 12,623 & \multirow{5}{*}{26,383} & \multirow{5}{*}{$\begin{array}{c}26,398 \\
\text { (no detail about } \\
\text { reactions) }\end{array}$} & \multirow{5}{*}{26,738} \\
\hline & ${ }^{28} \mathrm{Si}(\mathrm{n}, \alpha){ }^{25} \mathrm{Mg}$ & 2.75 & 8,195 & & & \\
\hline & ${ }^{28} \mathrm{Si}(\mathrm{n}, \mathrm{np}){ }^{27} \mathrm{Al}$ & 12.00 & 3,798 & & & \\
\hline & ${ }^{28} \mathrm{Si}(\mathrm{n}, \mathrm{d})^{27} \mathrm{Al}$ & 9.70 & 904 & & & \\
\hline & ${ }^{28} \mathrm{Si}(\mathrm{n}, \mathrm{n} \alpha){ }^{24} \mathrm{Mg}$ & 10.34 & 863 & & & \\
\hline \multirow{2}{*}{$\begin{array}{c}{ }^{29} \mathrm{Si} \\
(4.7 \%)\end{array}$} & ${ }^{29} \mathrm{Si}(\mathrm{n}, \alpha){ }^{26} \mathrm{Mg}$ & 0.035 & 379 & \multirow{2}{*}{729} & \multirow{2}{*}{708} & \multirow{2}{*}{846} \\
\hline & ${ }^{29} \mathrm{Si}(\mathrm{n}, \mathrm{p})^{29} \mathrm{Al}$ & 3.00 & 350 & & & \\
\hline \multirow{2}{*}{$\begin{array}{c}{ }^{30} \mathrm{Si} \\
(3.1 \%)\end{array}$} & ${ }^{30} \mathrm{Si}(\mathrm{n}, \alpha){ }^{27} \mathrm{Mg}$ & 4.34 & 137 & \multirow{2}{*}{207} & \multirow{2}{*}{170} & \multirow{2}{*}{496} \\
\hline & ${ }^{30} \mathrm{Si}(\mathrm{n}, \mathrm{p}){ }^{30} \mathrm{Al}$ & 8.00 & 70 & & & \\
\hline & & & TOTAL & 27,319 & 27,276 & 28,080 \\
\hline
\end{tabular}


Results of Table I and II show a good agreement between the three estimations in terms of global number of events for the different types of interactions and for the three isotopes of silicon. The numerical differences are within uncertainty margins inherent to Monte Carlo methods and to the extraction of the cross-section values from library data (extrapolation from discrete values at $2.45 \mathrm{MeV}$ and at $14.1 \mathrm{MeV}$ ).

For elastic events, the $1 \mathrm{keV}$ lower limit imposed in numerical simulations has the consequence of eliminating the less energetic recoils, that explains why the numbers of elastic events are slightly lower than those derived from direct calculation. The quantitative comparison between Geant4 and MCNP results shows that the two codes produce the same results in quasi all cases (within less than a few percents). The only notable difference is observed for the small amount of nonelastic events in the case of ${ }^{30} \mathrm{Si}$ for which important fluctuations are observed between the three evaluations without explanation at this level.

Finally, results of Table I and II also show that the same number of incident neutrons on a natural silicon target produce two time more interactions at $2.45 \mathrm{MeV}$ than at $14 \mathrm{MeV}$, respectively about $124 \mathrm{k}$ against $62 \mathrm{k}$ events. For a normalized incident neutron flux of $10 \mathrm{n} / \mathrm{cm}^{2} / \mathrm{s}$ (see section IV), this corresponds to an interaction rate $\left(\mathrm{R}_{\mathrm{I}}\right)$ of $2.48 \times 10^{-3} \mathrm{~s}^{-1}\left(\mathrm{R}_{\mathrm{I}} \approx 9 \mathrm{~h}^{-1}\right)$ at $2.45 \mathrm{MeV}$ and of $1.24 \times 10^{-3} \mathrm{~s}^{-1}\left(\mathrm{R}_{\mathrm{I}} \approx 4.5 \mathrm{~h}^{-1}\right)$ at $14 \mathrm{MeV}$ for the considered target. But the nature distributions of these interactions are profoundly different for these two energies. Figure 4 illustrates this aspect by cumulating the contributions of the different silicon isotopes for each category of interactions: results show that natural silicon subjected to $14 \mathrm{MeV}$ neutrons produces $40 \%$ of elastic events, $30 \%$ of inelastic and $30 \%$ of nonelastic events. At $2.45 \mathrm{MeV}$, no nonelastic event is produced; elastic events dominate the neutron silicon response with $75 \%$ of events against about $25 \%$ of events for inelastic interactions.

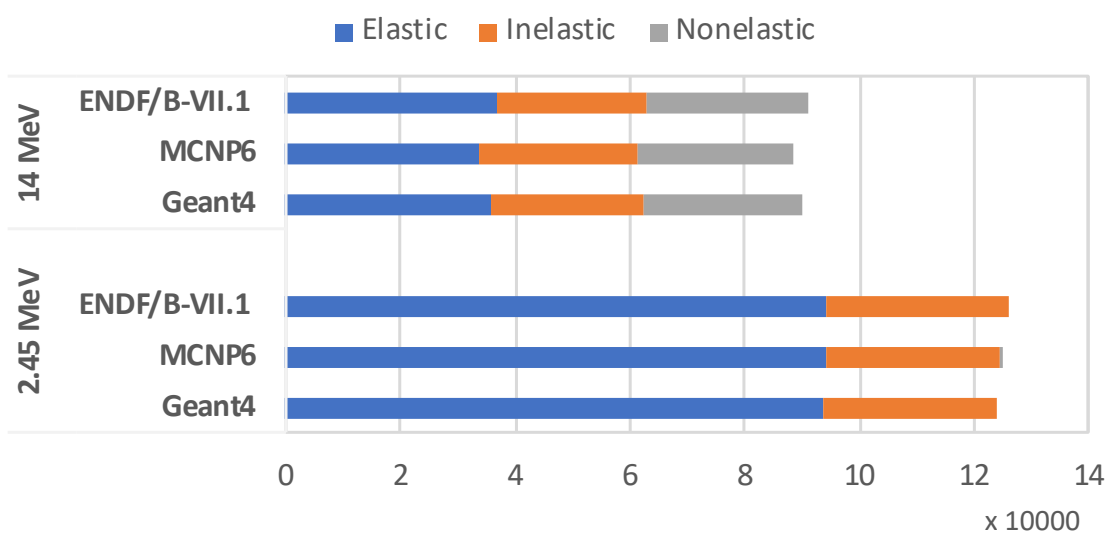

Figure 4. Comparisons between Geant4 and MCNP6 numerical simulations and direct calculations using EDNF/B-VII.1 nuclear data library. 


\section{B. Geant4 analysis of $n$-Si reactions}

Previous results having shown a very satisfactory agreement between Geant4 and MCNP simulation results, we focus in the following on Geant 4 results that allows us to explore in more details the nature of secondaries produced in $2.45 \mathrm{MeV}$ and $14 \mathrm{MeV}$ neutron-natural silicon interactions. Tables III and IV give the exact number of secondaries for each channel of reaction operating at $2.45 \mathrm{MeV}$ and $14 \mathrm{MeV}$, respectively, and also related to the three isotopes of silicon. The number of gamma photons is also indicated, although we already mentioned that they do not induce significant SEE in electronics; this information is just to remind that the gamma rays are in fact the most produced particles at this neutron energy. Excluding gamma rays from relevant products, results of Table IV show that, for $14 \mathrm{MeV}$ incident neutrons, silicon recoils from elastic and inelastic reactions represent $54 \%$ of all secondaries produced, followed by protons + deuterons and aluminum nuclei ( $15 \%$ each) and, finally, by alpha particles and magnesium nuclei ( $8 \%$ each). Note that, in the present case and due to the extremely limited number of reaction types, the number of protons+deuterons (resp. alpha particles) produced is strictly equal (ratio 1:1) to the number of aluminum nuclei (resp. magnesium nuclei) also produced. Table IV gives the distribution of isotopes for these two nuclei: ${ }^{28} \mathrm{Al}$ represents more than $70 \%$ of all aluminum produced and ${ }^{25} \mathrm{Mg}$ more than $85 \%$ of all magnesium nuclei.

Table III. Details of secondaries produced in a natural silicon target $\left(1 \mathrm{~cm}^{2} \times 20 \mu \mathrm{m}, 5 \times 10^{8} \mathrm{n}\right)$ by $2.45 \mathrm{MeV}$ neutron estimated from Geant4 simulations

\begin{tabular}{|c|c|c|c|}
\hline Secondary product & From reaction & Number & TOTAL \\
\hline \multirow{3}{*}{ Gamma } & ${ }^{28} \mathrm{Si}(\mathrm{n}, \mathrm{n})^{28} \mathrm{Si}^{*}$ (Inelastic) & 28,754 & \multirow{3}{*}{30,445} \\
\hline & ${ }^{29} \mathrm{Si}(\mathrm{n}, \mathrm{n}){ }^{29} \mathrm{Si}^{*}$ (Inelastic) & 1,397 & \\
\hline & ${ }^{30} \mathrm{Si}(\mathrm{n}, \mathrm{n}){ }^{30} \mathrm{Si}^{*}$ (Inelastic) & 294 & \\
\hline \multirow{2}{*}{${ }^{28} \mathrm{Si}$} & ${ }^{28} \mathrm{Si}(\mathrm{n}, \mathrm{n})^{28} \mathrm{Si}$ (Elastic) & 85,710 & \multirow{2}{*}{114,464} \\
\hline & ${ }^{28} \mathrm{Si}(\mathrm{n}, \mathrm{n})^{28} \mathrm{Si}^{*}$ (Inelastic) & 28,754 & \\
\hline \multirow{2}{*}{${ }^{29} \mathrm{Si}$} & ${ }^{29} \mathrm{Si}(\mathrm{n}, \mathrm{n})^{29} \mathrm{Si}$ (Elastic) & 4,335 & \multirow{2}{*}{5,732} \\
\hline & ${ }^{29} \mathrm{Si}(\mathrm{n}, \mathrm{n}){ }^{29} \mathrm{Si}^{*}$ (Inelastic) & 1,397 & \\
\hline \multirow{2}{*}{${ }^{30} \mathrm{Si}$} & ${ }^{30} \mathrm{Si}(\mathrm{n}, \mathrm{n}){ }^{30} \mathrm{Si}$ (Elastic) & 3,475 & \multirow{2}{*}{3,769} \\
\hline & ${ }^{30} \mathrm{Si}(\mathrm{n}, \mathrm{n}){ }^{30} \mathrm{Si}^{*}$ (Inelastic) & 294 & \\
\hline
\end{tabular}


Table IV. Details of secondaries produced in a natural silicon target $\left(1 \mathrm{~cm}^{2} \times 20 \mu \mathrm{m}, 5 \times 10^{8} \mathrm{n}\right)$ by $14 \mathrm{MeV}$ neutrons estimated from Geant4 simulations.

\begin{tabular}{|c|c|c|c|c|}
\hline Secondary product & From reaction & Number & TOTAL & TOTAL (Z) \\
\hline Gamma & $\begin{array}{l}\text { From all inelastic and nonelastic } \\
\text { reactions }\end{array}$ & 137,119 & 137,119 & - \\
\hline \multirow{4}{*}{ Protons } & ${ }^{28} \mathrm{Si}(\mathrm{n}, \mathrm{p})^{28} \mathrm{Al}$ & 12,623 & \multirow{4}{*}{16,841} & \multirow{5}{*}{$\begin{array}{c}17,745 \\
(Z=1)\end{array}$} \\
\hline & ${ }^{28} \mathrm{Si}(\mathrm{n}, \mathrm{np})^{27} \mathrm{Al}$ & 3,798 & & \\
\hline & ${ }^{29} \mathrm{Si}(\mathrm{n}, \mathrm{p}){ }^{29} \mathrm{Al}$ & 350 & & \\
\hline & ${ }^{30} \mathrm{Si}(\mathrm{n}, \mathrm{p})^{30} \mathrm{Al}$ & 70 & & \\
\hline Deuterons & ${ }^{28} \mathrm{Si}(\mathrm{n}, \mathrm{d})^{27} \mathrm{Al}$ & 904 & 904 & \\
\hline \multirow{4}{*}{ Alphas } & $\left.{ }^{28} \mathrm{Si}(\mathrm{n}, \alpha)\right)^{25} \mathrm{Mg}$ & 8,195 & \multirow{4}{*}{9,574} & \multirow{4}{*}{$\begin{array}{l}9,574 \\
(Z=2)\end{array}$} \\
\hline & $\left.{ }^{28} \mathrm{Si}(\mathrm{n}, \mathrm{n} \alpha)\right)^{24} \mathrm{Mg}$ & 863 & & \\
\hline & ${ }^{29} \mathrm{Si}(\mathrm{n}, \alpha)^{26} \mathrm{Mg}$ & 379 & & \\
\hline & ${ }^{30} \mathrm{Si}(\mathrm{n}, \alpha)^{27} \mathrm{Mg}$ & 137 & & \\
\hline${ }^{24} \mathrm{Mg}$ & ${ }^{28} \mathrm{Si}(\mathrm{n}, \mathrm{n} \alpha)^{24} \mathrm{Mg}$ & 863 & 863 & \multirow{4}{*}{$\begin{array}{l}9,574 \\
(Z=12)\end{array}$} \\
\hline${ }^{25} \mathrm{Mg}$ & ${ }^{28} \mathrm{Si}(\mathrm{n}, \alpha){ }^{25} \mathrm{Mg}$ & 8,195 & 8,195 & \\
\hline${ }^{26} \mathrm{Mg}$ & ${ }^{29} \mathrm{Si}(\mathrm{n}, \alpha)^{26} \mathrm{Mg}$ & 379 & 379 & \\
\hline${ }^{27} \mathbf{M g}$ & ${ }^{30} \mathrm{Si}(\mathrm{n}, \alpha)^{27} \mathrm{Mg}$ & 137 & 137 & \\
\hline \multirow{2}{*}{${ }^{27} \mathbf{A l}$} & ${ }^{28} \mathrm{Si}(\mathrm{n}, \mathrm{np})^{27} \mathrm{Al}$ & 3,798 & \multirow{2}{*}{4,702} & \multirow{5}{*}{$\begin{array}{l}17,745 \\
(Z=13)\end{array}$} \\
\hline & ${ }^{28} \mathrm{Si}(\mathrm{n}, \mathrm{d})^{27} \mathrm{Al}$ & 904 & & \\
\hline${ }^{28} \mathrm{Al}$ & ${ }^{28} \mathrm{Si}(\mathrm{n}, \mathrm{p})^{28} \mathrm{Al}$ & 12,623 & 12,623 & \\
\hline${ }^{29} \mathrm{Al}$ & ${ }^{29} \mathrm{Si}(\mathrm{n}, \mathrm{p})^{29} \mathrm{Al}$ & 350 & 350 & \\
\hline${ }^{30} \mathrm{Al}$ & ${ }^{30} \mathrm{Si}(\mathrm{n}, \mathrm{p})^{30} \mathrm{Al}$ & 70 & 70 & \\
\hline \multirow{2}{*}{${ }^{28} \mathrm{Si}$} & ${ }^{28} \mathrm{Si}(\mathrm{n}, \mathrm{n})^{28} \mathrm{Si}$ (Elastic) & 32,812 & \multirow{2}{*}{56,854} & \multirow{6}{*}{$\begin{array}{l}62,475 \\
(Z=14)\end{array}$} \\
\hline & ${ }^{28} \mathrm{Si}(\mathrm{n}, \mathrm{n})^{28} \mathrm{Si}^{*}$ (Inelastic) & 24,042 & & \\
\hline \multirow{2}{*}{${ }^{29} \mathrm{Si}$} & ${ }^{29} \mathrm{Si}(\mathrm{n}, \mathrm{n}){ }^{29} \mathrm{Si}$ (Elastic) & 1,705 & \multirow{2}{*}{3,615} & \\
\hline & ${ }^{29} \mathrm{Si}(\mathrm{n}, \mathrm{n}){ }^{29} \mathrm{Si}^{*}$ (Inelastic) & 1,910 & & \\
\hline \multirow{2}{*}{${ }^{30} \mathrm{Si}$} & ${ }^{30} \mathrm{Si}(\mathrm{n}, \mathrm{n}){ }^{30} \mathrm{Si}$ (Elastic) & 1,113 & \multirow{2}{*}{2,006} & \\
\hline & ${ }^{30} \mathrm{Si}(\mathrm{n}, \mathrm{n}){ }^{30} \mathrm{Si}^{*}$ (Inelastic) & 893 & & \\
\hline
\end{tabular}



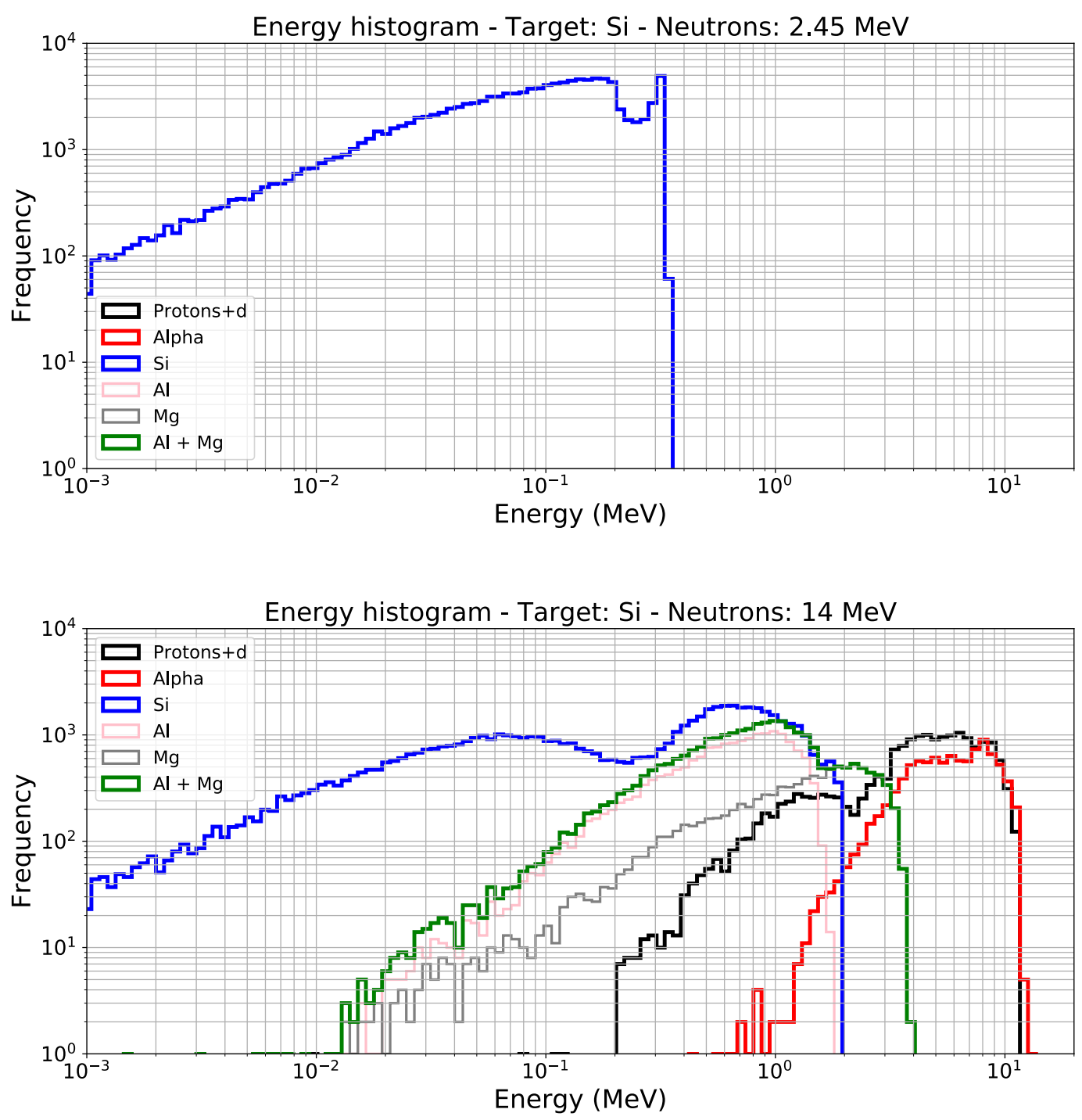

Figure 5. Energy histograms of silicon nuclei recoils and secondaries produced in a natural silicon target $\left(1 \mathrm{~cm}^{2}\right.$ $\times 20 \mu \mathrm{m}, 5 \times 10^{8} \mathrm{n}$ ) by $2.45 \mathrm{MeV}$ and $14 \mathrm{MeV}$ neutrons deduced from Geant 4 simulations.

Beyond this quantitative aspect, energy spectra for all these products have been computed as well as their initial LET and range distributions in silicon material. Figure 5 shows the energy histograms of silicon nuclei recoils and secondaries produced as deduced from simulation runs at 2.45 and $14 \mathrm{MeV}$. Silicon recoils form a continuum from the lowest energies (10 $\mathrm{keV}$ in this case) up to a maximum energy Emax than can be given by the incident neutron to the recoil and theoretically equal to [16]:

$$
E_{\text {max }}=4 \times E \times \frac{A}{(A+1)^{2}}
$$

where $\mathrm{A}$ is the mass number of the target nucleus and $\mathrm{E}$ is the incident neutron energy. 
Here, for $\mathrm{A}=28$, we obtain $\mathrm{E}_{\max }=0.33 \mathrm{MeV}$ for $2.45 \mathrm{MeV}$ neutrons and $\mathrm{E}_{\max }=1.86 \mathrm{MeV}$ for $14 \mathrm{MeV}$ neutrons, in excellent agreement with the cutoff values extracted from Figure 5, respectively $\approx 0.34 \mathrm{MeV}$ and $\approx 2$ $\mathrm{MeV}$.

For other secondaries produced in $14 \mathrm{MeV}$ neutron-silicon interactions, similar continuum and increasing distributions, starting at a low energy typically well below $1 \mathrm{MeV}$ and brutally cutting at a higher energy of a few $\mathrm{MeV}$, are obtained on shorter energy ranges, typically from $10^{-2} \mathrm{MeV}$ to $2 \mathrm{MeV}$ (resp. $4 \mathrm{MeV}$ ) for $\mathrm{Al}$ (resp. $\mathrm{Mg}$ ) nuclei, from 0.2 to $11 \mathrm{MeV}$ for protons and from 0.8 to $12 \mathrm{MeV}$ for alpha particles. Protons and alpha particles thus constitute the most energetic particles produced in $\mathrm{n}-\mathrm{Si}$ interactions.

From data of Figure 5, we deduced the initial LET (Figure 6) and range (Figure 7) distributions in silicon for these different categories of secondary products. For memory [15], the initial LET corresponds to the particle energy lost by unit of length due to electronic collision mechanisms just after the particle is emitted. The range corresponds to the distance traveled by the particle from its emission point until it comes to rest. Both quantities depend on the nature of the particle and on the nature of the medium (target material) in which the particle travels.
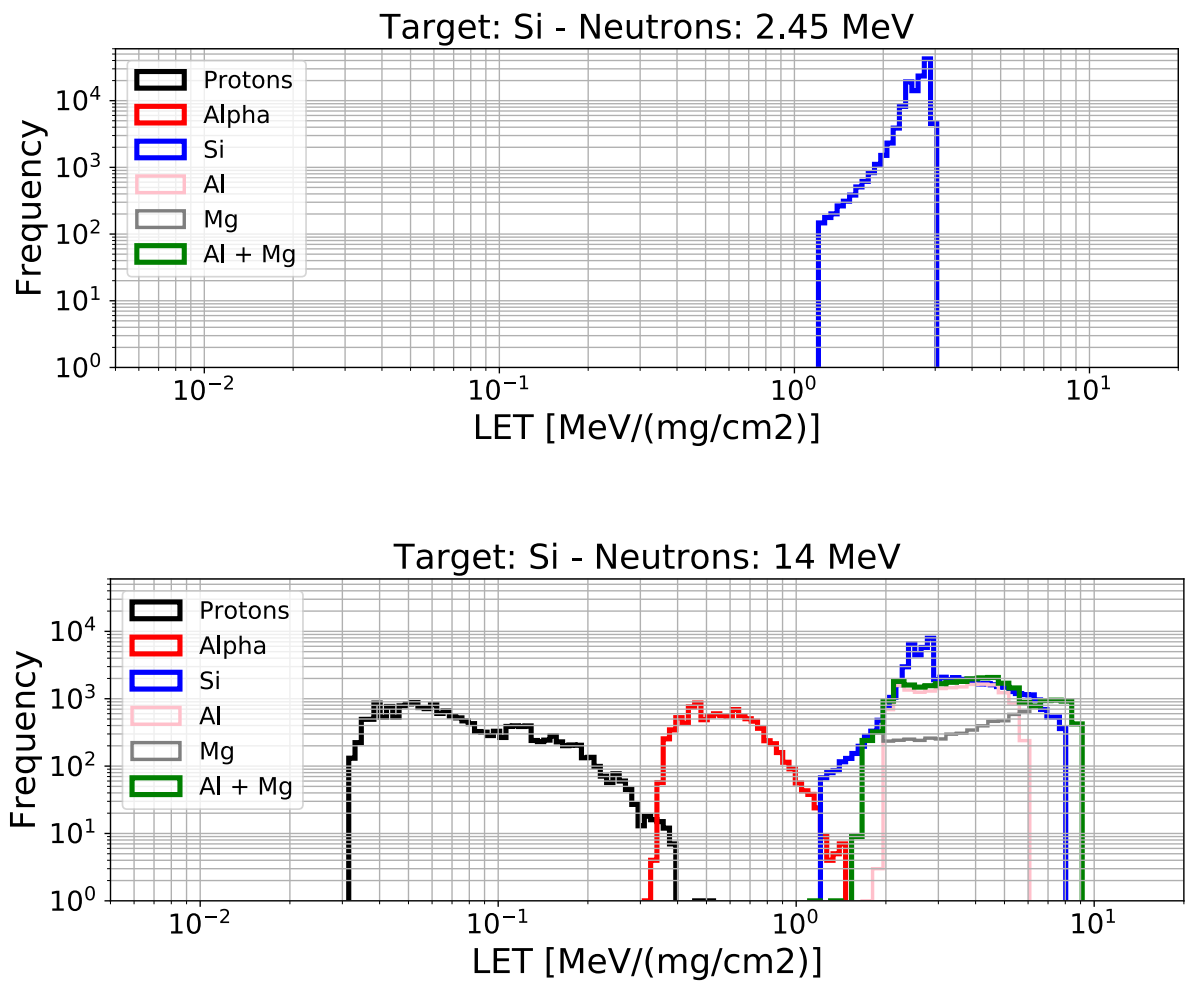

Figure 6. Initial LET histograms of all secondary particles produced in a natural silicon target $\left(1 \mathrm{~cm}^{2} \times 20 \mu \mathrm{m}\right.$, $5 \times 10^{8} \mathrm{n}$ ) by $2.45 \mathrm{MeV}$ and $14 \mathrm{MeV}$ neutrons deduced from Geant4 simulations and SRIM data. 

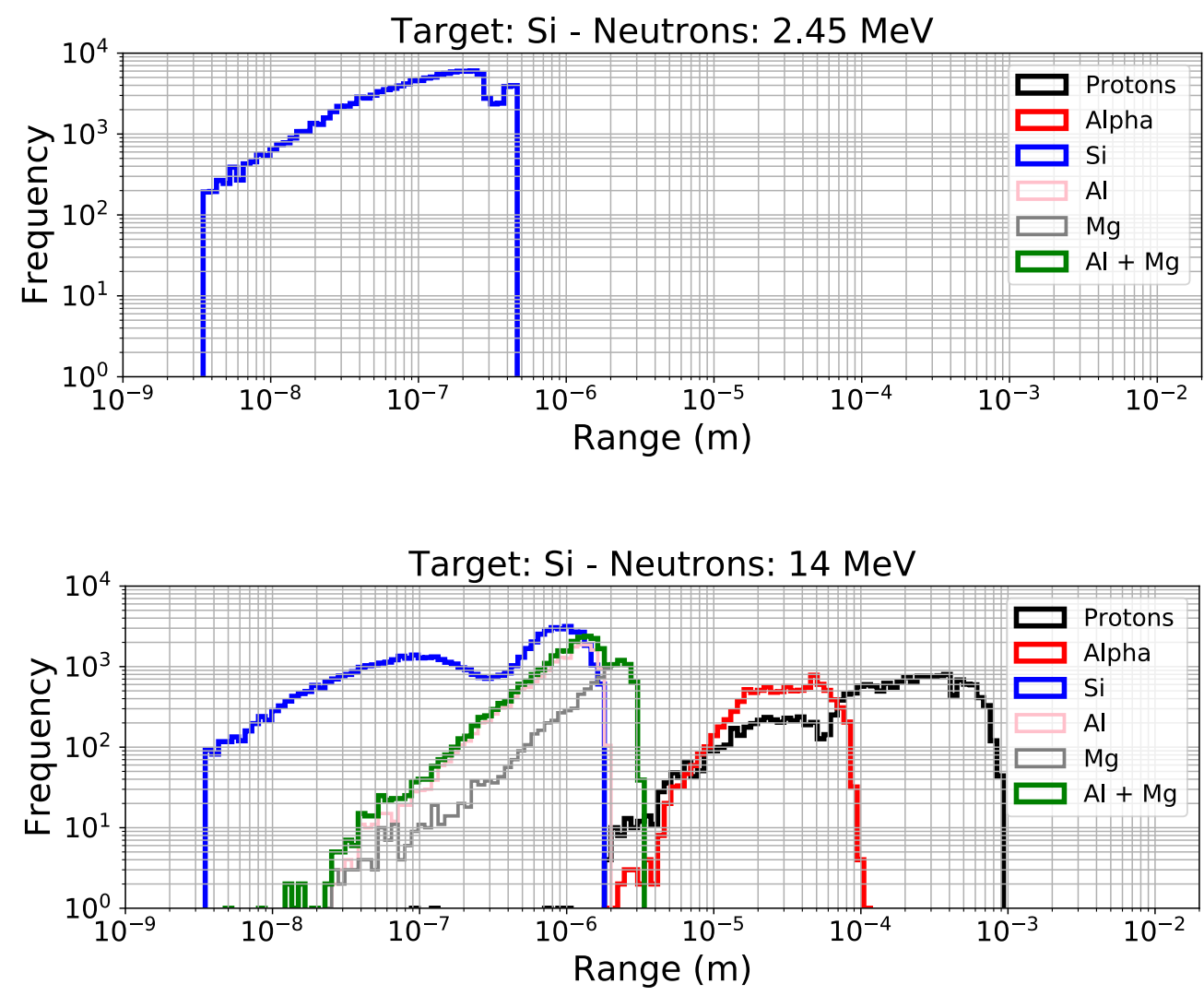

Figure 7. Range histograms of all secondary particles produced in a natural silicon target $\left(1 \mathrm{~cm}^{2} \times 20 \mu \mathrm{m}, 5 \times 10^{8}\right.$ n) by $2.45 \mathrm{MeV}$ and $14 \mathrm{MeV}$ neutrons deduced from Geant4 simulations and SRIM data.

Beyond the differences between the raw numbers of secondary particles produced, Figures 6 and 7 highlight large differences in LET and range distributions for the two considered incident neutron energies. For $2.45 \mathrm{MeV}$ incident neutrons, the LET distribution of silicon recoils is relatively narrow, in the range of 1 to $3 \mathrm{MeV} /\left(\mathrm{mg} / \mathrm{cm}^{2}\right)$; the corresponding ranges in silicon are short, typically in the nanometer range and always below a few tenths of a micron. At $14 \mathrm{MeV}$, Figures 6 and 7 show that, logically, the lightest particles in mass, the protons, exhibit the lowest LET values, in the interval from $10^{-2}$ to a few $10^{-1} \mathrm{MeV} /\left(\mathrm{mg} / \mathrm{cm}^{2}\right)$, and the highest ranges in silicon, typically from micron to millimeter. Alpha particles are characterized by intermediate values, with typical initial LET values between 0.3 to $1.5 \mathrm{MeV} /\left(\mathrm{mg} / \mathrm{cm}^{2}\right)$ and ranges in the domain from the micron to one tenth of millimeter. Finally, Si recoils, $\mathrm{Al}$ and $\mathrm{Mg}$ nuclei exhibit the highest initial LET values, from 1 to $9 \mathrm{MeV} /\left(\mathrm{mg} / \mathrm{cm}^{2}\right)$ and the lowest ranges, from the nanometer to a maximum of a few microns. As discussed in the next sections and on the basis of these quantitative results, all the secondaries resulting from n-Si interactions will not play the same role in the creation of possible single event events in silicon electronics. 


\section{Implications for reliability electronics of future power fusion machines}

Future power fusion reactors, like ITER or DEMO, will be very large machines characterized by a very large number of electronic equipment's for all operations of control commands, safety diagnosis and information management [17]. Dispersed in the reactor building, around the reactor chamber, these equipment's will be subjected to a machine-induced radiation environment. For these future machines and in order to reduce the cost of electronics, the most plausible design strategy for electronics will be (1) to drastically limit the need of radiationhardened electronics installed in the severe environment close to the tokamak chamber by deporting and installing electronics in radiation protected area (RPA) and (2) to standardize as much as possible the radiation-hardened electronics needed in the severe environment close to the tokamak chamber. In these RPAs, the radiation conditions (neutrons and total ionizing dose TID) are expected to be compatible with the level of electronics reliability requested for machine operation. A large fusion machine such as a tokamak has many auxiliary systems, each of which requires complex instrumentation with many I\&C electronic cabinets. For instance, a recent rough engineering estimation for the ITER Project shows that the reactor building will house more than five hundred I\&C electronic cabinets [18] containing various types of semiconductor devices (analogue devices, digital devices, optoelectronic devices, power devices, switching devices,...), and that modern I\&C electronics cabinet such as those to be used in ITER can typically house up to 30,000 to 40,000 semiconductor devices [18]. Considering conservatively only 300 cabinets and applying a conservative $50 \%$ fill factor results in about five million semiconductor devices. This conservative rough estimate can be considered as representative of modern fusion machines. Although a very large proportion of these devices will be installed in RPAs, the radiation shielding of these later risks, for technical and cost reasons, to be not sufficient to totally screen the "high energy" $(\mathrm{E}>1 \mathrm{MeV})$ neutron flux produced in the tokamak plasma (the problematic of low energy and thermal neutrons is considered to be solved by properly shielding the RPAs with appropriate materials and thicknesses). In the following and in order to illustrate this point, we choose a very plausible value of $10 \mathrm{n} / \mathrm{cm}^{2} / \mathrm{s}$ as the maximal residual total neutron flux $(\mathrm{E}>1 \mathrm{MeV})$ tolerated in RPAs. This value will necessarily result from a compromise between the reduction of the radiation level, the size, the weight and the financial cost of the neutron shielding structures. For machines like ITER or DEMO, such a residual value corresponds to a fantastic shielding reduction factor, around $10^{12}$ to $10^{13}$, in the total neutron flux generated in the fusion plasma. But compared to the natural comic-ray induced neutron flux at sea level which is equal to $20 \mathrm{n} / \mathrm{cm}^{2} / \mathrm{h}(\mathrm{E}>1 \mathrm{MeV})$ [15], i.e. $5 \times 10^{-3} \mathrm{n} / \mathrm{cm}^{2} / \mathrm{s}$; it represents 2,000 times the terrestrial neutron flux but with an energy distribution of neutrons, of course, very different. At this stage, without an accurate knowledge of the neutron flux energy distributions in RPAs for machine operation with D-D 
or D-T plasmas, a limit case can be envisaged as a "worst case" to roughly estimate the impact of machine-induced neutrons on electronics: that of considering this residual flux of $10 \mathrm{n} / \mathrm{cm}^{2} / \mathrm{s}$ inside RPAs is composed only of 2.45 or $14 \mathrm{MeV}$ neutrons. From simulation results reported in section II, we estimated under this flux a global interaction rate $\mathrm{R}_{\mathrm{I}}=2.48 \times 10^{-3} \mathrm{~s}^{-1}\left(\approx 9 \mathrm{~h}^{-1}\right)$ at $2.45 \mathrm{MeV}$ and $\mathrm{R}_{\mathrm{I}}=1.24 \times 10^{-3} \mathrm{~s}^{-1}\left(\approx 4.5 \mathrm{~h}^{-1}\right)$ at $14 \mathrm{MeV}$ for the considered target $\left(1 \mathrm{~cm}^{2} \times 20 \mu \mathrm{m}\right)$. These values represent an "upper limit" for the interactions at silicon level potentially responsible of SEEs at semiconductor device level in electronics. In the same time, it should be noted that state-of-the-art chip technologies contain many more materials (different atoms and their isotopes), especially in the vicinity of the sensitive drain junctions (for instance drain and pocket implants [19], gate and contact materials, etc.). Even though these interactions could be lower in number owing to the lower number of atoms or be more distant than those occurring in silicon close to the sensitive drains, they could potentially generate additional secondaries (also with higher LET) that may increase these estimations of the interaction rates.

On the basis of the interaction rates restricted to $\mathrm{n}-\mathrm{Si}$ interactions, the following estimations can be easily derived: for $\mathrm{N}=5$ million chips on board with a typical silicon surface of $\mathrm{S}=10 \mathrm{~mm}^{2}$ per chip, we obtain a total of $\mathrm{N} \times \mathrm{S} \times \mathrm{R}_{\mathrm{I}}=4.48 \times 10^{6}$ interactions per hour at $2.45 \mathrm{MeV}$ and $2.23 \times 10^{6}$ at $14 \mathrm{MeV}$ susceptible, for a fraction of them, to induce problematic SEEs at semiconductor device level (the impact at system level, which depends on the system architecture, is outside the scope of the present study). For modern digital electronics, if in addition we consider that:

i) $\quad 2.45 \mathrm{MeV} \mathrm{n}-\mathrm{Si}$ interactions (exclusively composed of elastic and nonelastic events characterized by very short ranges, see Figure 7) are approximately 4 times less efficient than $14 \mathrm{MeV}$ n-Si interactions (one third are nonelastic events with more energetic and "long range" products as protons and alpha which represent much more dangerous particles in terms of SEE's occurrence and magnitude) to induce SEEs as evidenced in [20];

ii) only a very small fraction of $\eta=0.1 \%$ of these events cannot be corrected by error correcting codes (ECC) in logic devices and potentially conduct to "problematic" SEEs (high performance ECC can recover more than $99 \%$ of the errors [21], we consider here an efficiency value of $99.9 \%$ );

then this trivial calculation shows that, for five million semiconductor devices estimated in the reactor building of a fusion machine, the magnitude of the failure rate at semiconductor device level should be in the order of $\mathrm{N} \times \mathrm{S} \times \mathrm{R}_{\mathrm{I}} \times \eta=0.65 \mathrm{SEE} / \mathrm{s}$ at $14 \mathrm{MeV}$ and $\left(\mathrm{N} \times \mathrm{S} \times \mathrm{R}_{\mathrm{I}} \times \eta\right) / 4=0.3 \mathrm{SEE} / \mathrm{s}$ at $2.45 \mathrm{MeV}$. This typically represents, for a tokamak plasma pulse duration of 10 minutes $(600 \mathrm{~s})$, a maximum of 180 potentially « problematic » SEEs in D-D plasma operation, and around 375 SEEs in D-T plasma operation. We would like immediately insist on the 
roughly character of these first worst case estimations, due to an extreme simplification of the inputs and on the calculation hypothesis: 1) neutrons will not be monoenergetic and their energy will be degraded when a fraction of them will penetrate in RPAs, 2) electronics will not be fully digital and a part of the five million of devices will be analogue, optoelectronics or power components characterized by other neutron sensitivity mechanisms, 3) the fraction of "problematic" events is difficult to generalize and to evaluate for all future components and circuits of electronic equipment of large fusion machines, 4) soft and hard error mitigation at system level (beyond ECC at circuit level) is ignored. All these precautions being said, the fact remains that the calculated orders of magnitude is certainly realistic and have the merit of showing that a residual flux of neutrons in the RPAs, as low as 10 $\mathrm{n} / \mathrm{cm}^{2} / \mathrm{s}$, will inevitably lead to potentially problematic SEE neutron events in the electronics at device level during machine operation, with both D-D and D-T plasmas.

The next steps of this exploration study will be to use the Geant4 databases computed in this work to more accurately estimate the occurrence of SEEs in a series of generic devices representative of tokamak electronics and also to refine all the calculations by considering neutron spectral distributions in the RPAs when such data will be available. Synergy effects between neutron irradiation and TID (expected to be in the range of 1-10 Gy(Si) in the RPAs) should be also investigated. The refined estimates of the occurrence of SEE at the device level, which should be provided by this next stage of study, could then be used as input to estimate the impact of SEEs on the reliability of the various auxiliary systems of a fusion machine.

\section{Conclusion}

This study is the first work of a series of investigations dedicated to the predictive evaluation of future power fusion machine electronics reliability in both D-D and D-T plasma operations. We started from the most simplified case of a natural silicon target, representative of the sensitive volume of an integrated circuit, subjected to monoenergetic $2.45 \mathrm{MeV}$ and $14 \mathrm{MeV}$ neutrons. The computation and the analysis of the interaction event databases allowed us to classify and quantify the different types of interactions and the neutron-induced secondary products as a function of their type, energy, linear energy transfer and range in silicon. This inventory and classification work constitute the first mandatory step for all physics-based computation of electronic circuit responses in the residual radiation environment. On the basis of this quantitative tableau and pending further more complete works, we tried to estimate very roughly the rate of single events at semiconductor device level in the overall electronics of a future power fusion machine, located in radiation-protected areas and therefore subjected to a residual neutron flux, here assumed to be monoenergetic. Our numerical estimations show that, in the current 
state of knowledge, the event rate magnitude at semiconductor device level, not only for D-T plasma but also for D-D plasma operation, is potentially questionable and must be considered with extreme attention in the global evaluation of the fusion machine reliability in operation.

\section{References}

[1] E. Morse, “Nuclear Fusion”, Springer Nature Switzerland AG (2018)

[2] G.C. Messenger, M.S. Ash, 1997. “Single Event Phenomena”. Dordrecht: Springer (1997)

[3] C.J. Werner, et al., "MCNP6.2 Release Notes”, Los Alamos National Laboratory, report LA-UR-18-20808 (2018)

[4] C.J. Werner (editor), “MCNP User's Manual - Code Version 6.2”, Los Alamos National Laboratory, report LA-UR-17-29981 (2017).

[5] S. Agostinelli et al., "Geant4 - a simulation toolkit", Nuclear Instruments and Methods in Physics Research Section A: Accelerators, Spectrometers, Detectors and Associated Equipment, vol. 506, no. 3, pp. 250-303 (2003). [6] J. Allison, K. Amako, J. Apostolakis, P. Arce, M. Asai et al., "Recent developments in Geant4", Nuclear Instruments and Methods in Physics Research Section A: Accelerators, Spectrometers, Detectors and Associated Equipment, vol. 835, pp. 186-225 (2016).

[7] M.B. Chadwick et al, "ENDF/B-VII.1: Nuclear Data for Science and Technology: Cross Sections, Covariances, Fission Product Yields and Decay Data”, Nuclear Data Sheets, Vol. 112, pp. 2887-2996 (2011).

[8] Sigma Evaluated Nuclear Data File (ENDF) Retrieval \& Plotting, National Nuclear Data Center, Brookhaven National Laboratory, available online: https:/www.nndc.bnl.gov/sigma/

[9] D. Munteanu, J.L. Autran, "Susceptibility of Group-IV and III-V Semiconductor-based Electronics to Atmospheric Neutrons Explored by Geant4 Numerical Simulations", in "Numerical Simulations", Numerical Simulations, Numerical Simulations in Engineering and Science, Srinivas P. Rao, IntechOpen, Chapter 7, p. 234255 (2017)

[10] J.L. Autran, D. Munteanu, “Atmospheric Neutron Radiation Response of III-V Binary Compound Semiconductors", IEEE Transactions on Nuclear Science, Vol. 67, no. 7, pp. 1428-1435 (2020).

[11] D. Munteanu, J.L. Autran, "Interactions between Terrestrial Cosmic-Ray Neutrons and III-V Compound Semiconductors", Modeling and Simulation in Engineering - Selected Problems, Jan Valdman and Leszek Marcinkowski, IntechOpen, DOI: 10.5772/intechopen.92774. 
[12] Geant4 reference physics list, available online: https://geant4.web.cern.ch/node/155

[13] J. F. Ziegler, J. P. Biersack, M. D. Ziegler, "SRIM - The Stopping and Range of Ions in Matter". SRIM Co., 2008, ISBN 0-9654207-1-X.

[14] SRIM-2013 code, available online : http://srim.org

[15] J.L. Autran, D. Munteanu, "Soft Errors: from particles to circuits". Taylor \& Francis/CRC Press (2015).

[16] R. Gaillard, "Single Event Effects: Mechanisms and Classification". In M. Nicolaidis (Ed.), "Soft Errors in Modern Electronic Systems”. New York: Springer (2011).

[17] G. McCracken, P. Stott, "Fusion, The Energy of the Universe", Oxford: Academic Press (2012)

[18] ITER Organization, private communication.

[19] J.L. Autran, S. Serre, S. Semikh, D. Munteanu, G. Gasiot, P. Roche, "Soft-Error Rate Induced by Thermal and Low Energy Neutrons in $40 \mathrm{~nm}$ SRAMs", IEEE Transactions on Nuclear Science, 2012, Vol. 59, no. 6, p. $2658-2665$.

[20] S. Serre, S. Semikh, S. Uznanski, J.L. Autran, D. Munteanu, G. Gasiot, P. Roche, "Geant4 Analysis of n-Si Nuclear Reactions From Different Sources of Neutrons and Its Implication on Soft-Error Rate", IEEE Transactions on Nuclear Science, Vol. 59, no. 4, pp. 714-722 (2012).

[21] J.J. Meza. "Large Scale Studies of Memory, Storage, and Network Failures in a Modern Data Center", PhD Thesis, Carnegie Mellon University Pittsburgh, PA (2018). 